\title{
Basal Ganglia Volume Is Associated with Aerobic Fitness in Preadolescent Children
}

\author{
Laura Chaddock $^{\mathrm{a}}$ Kirk I. Erickson ${ }^{\mathrm{c}}$ Ruchika Shaurya Prakash ${ }^{\mathrm{d}}$ Matt VanPatter $^{\mathrm{a}}$ \\ Michelle W. Voss ${ }^{a}$ Matthew B. Pontifex ${ }^{b}$ Lauren B. Raine ${ }^{b}$ Charles H. Hillman ${ }^{b}$ \\ Arthur F. Kramer ${ }^{\mathrm{a}}$
}

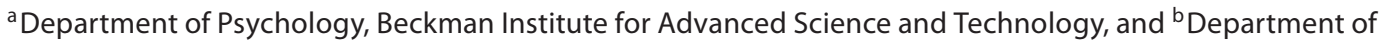
Kinesiology and Community Health, University of Illinois at Urbana-Champaign, Urbana, III., 'Department of Psychology, University of Pittsburgh, Pittsburgh, Pa., and d Department of Psychology, Ohio State University, Columbus, Ohio, USA

\section{Key Words}

Brain · Development $\cdot$ Exercise $\cdot \mathrm{MRI} \cdot$ Physical activity

Neurocognition $\cdot$ Neuroimaging $\cdot$ Striatum

\begin{abstract}
The present investigation is the first to explore the association between childhood aerobic fitness and basal ganglia structure and function. Rodent research has revealed that exercise influences the striatum by increasing dopamine signaling and angiogenesis. In children, higher aerobic fitness levels are associated with greater hippocampal volumes, superior performance on tasks of attentional and interference control, and elevated event-related brain potential indices of executive function. The present study used magnetic resonance imaging to investigate if higher-fit and lower-fit 9-and 10-year-old children exhibited differential volumes of other subcortical brain regions, specifically the basal ganglia involved in attentional control. The relationship between aerobic fitness, dorsal and ventral striatum volumes and performance on an attention and inhibition Eriksen flanker task was also examined. The results indicated that higher-fit children showed superior flanker task performance compared to lower-fit children. Higher-fit children also showed greater volumes of the dorsal striatum, and dorsal striatum volume was negatively associated with behavioral interference. The
\end{abstract}

results support the claim that the dorsal striatum is involved in cognitive control and response resolution and that these cognitive processes vary as a function of aerobic fitness. No relationship was found between aerobic fitness, the volume of the ventral striatum and flanker performance. The findings suggest that increased childhood aerobic fitness is associated with greater dorsal striatal volumes and that this is related to enhanced cognitive control. Because children are becoming increasingly overweight, unhealthy and unfit, understanding the neurocognitive benefits of an active lifestyle during childhood has important public health and educational implications.

Copyright $\odot 2010$ S. Karger AG, Basel

\section{Introduction}

Aerobic exercise and physical activity improve brain and cognitive health across the lifespan [Hillman et al., 2008]. While the prefrontal cortex and the hippocampus are the focus of many human and animal studies of fitness and neurocognition [Chaddock et al., 2010; Chaddock et al., in press; Colcombe and Kramer, 2003; Cotman and Berchtold, 2002; Erickson et al., 2009; Hillman et al., 2009; Lopez-Lopez et al., 2004; Neeper et al., 1995; van Praag et al., 1999, 2005; Vaynman et al., 2004], rodent

\section{KARGER}

Fax +41613061234 E-Mail karger@karger.ch www.karger.com
(C) 2010 S. Karger AG, Basel

0378-5866/10/0323-0249\$26.00/0

Accessible online at:

www.karger.com/dne
Laura Chaddock

Department of Psychology, Beckman Institute for Advanced Science and Technology University of Illinois at Urbana-Champaign

405 North Mathews Avenue, Urbana, IL 61801 (USA)

Tel. +1 610209 6836, Fax +1 217333 2922, E-Mail lchaddo2@illinois.edu 
research indicates that wheel running also influences the molecular architecture and behavior of the basal ganglia. The basal ganglia are a group of structures subdivided into the dorsal striatum, a subregion implicated in stimulus-response challenges that require response selection demands, motor integration, response resolution, cognitive flexibility and the execution of learned behaviors, and the ventral striatum, part of an affect and reward pathway involved in reinforcement learning and motivational states [Aron et al., 2009; Casey et al., 2008; Di Martino et al., 2008; Draganski et al., 2008; Graybiel, 2005, 2008; Ragozzino et al., 2002]. Exercise has been shown to increase the production and secretion of striatal brainderived neurotrophic factor [Aguiar et al., 2008; Marais et al., 2009] and dopamine [Marques et al., 2008] as well as increase astrocyte proliferation [Li et al., 2005] and neural activity [Shi et al., 2004] in the striatum. In addition, exercise induces angiogenesis and reduces the damaging effects of 6-hydroxydopamine to dopamine neurons in the basal ganglia [Ding et al., 2004; Tillerson et al., 2001].

The present study is the first to explore the association between aerobic fitness and striatum volume and function in humans. A preadolescent population was examined to add to an emerging literature that physical activity and high levels of aerobic fitness during childhood may enhance neurocognition [Buck et al., 2008; Castelli et al., 2007; Chaddock et al., 2010; Chaddock et al., in press; Chomitz et al., 2009; Hillman et al., 2005, 2008; Sibley and Etnier, 2003]. The investigation builds on our prior work which showed a positive association between aerobic fitness, hippocampal volume and memory performance in preadolescent children [Chaddock et al., 2010]. In the present study we investigate the relationship between fitness and additional brain regions, in particular the basal ganglia, to understand if higher aerobic fitness in children can affect other regional brain volumes involved in cognitive task performance.

To this end, the present investigation examined the relationship between aerobic fitness, the volume of the dorsal and ventral striatum, and flanker task performance. A recent behavioral and event-related potential study by Hillman et al. [2008] suggested improved selective attention, interference control and action monitoring for higher-fit relative to lower-fit preadolescents during the flanker task [see Colcombe et al., 2004 for a similar observation with older adults]. Given that the basal ganglia have an important role in cognitive control (e.g. preparing, initiating, inhibiting, switching responses) [Aron et al., 2009], a key skill involved in the performance of the flanker paradigm, it is possible that fitness differences in flanker task performance and event-related potential indices are related to differences in the volume of the striatum. In addition, the basal ganglia have been implicated as an important component of the neural circuitry involved in the flanker paradigm [Casey et al., 2000; Wylie et al., 2009]. Thus, higher-fit and lower-fit participants were expected to show different striatal volume patterns that were related to differential flanker task performance.

\section{Method}

\section{Participants}

Preadolescent 9- and 10-year-old children were recruited from East-Central Illinois. The children were screened for several factors that influence fitness or cognitive function. Relatively strict screening criteria were employed to help ensure that the fitness groups did not differ on variables that could potentially bias cognitive function or basal ganglia volume. To begin, the Kaufman Brief Intelligence Test [Kaufman and Kaufman, 1990] was administered to each child to obtain a composite intelligence quotient (IQ) score including both crystallized and fluid intelligence measures. Subjects were excluded if their scores were $>1$ standard deviation below the mean (85\%). Next, a guardian of the child completed the Attention Deficit Hyperactivity Disorder (ADHD) Rating Scale IV [DuPaul et al., 1998] to screen for the presence of attentional disorders. Participants were excluded if they scored above the 85 th percentile. Pubertal timing was also assessed using a modified Tanner Staging System [Tanner, 1962; Taylor et al., 2001] with all included prepubescent participants at or below a score of 2 on a 5 -point scale of developmental stages. In addition, socioeconomic status was determined by creating a trichotomous index based on 3 variables: participation in a free or reduced-price lunch program at school, the highest level of education obtained by the mother and father, and the number of parents who worked full-time [Birnbaum et al., 2002].

Furthermore, eligible participants were required to (1) qualify as higher-fit or lower-fit (i.e. subjects with fitness levels between these 2 extremes were excluded from participation; see 'Aerobic Fitness Assessment' section), (2) demonstrate right-handedness (as measured by the Edinburgh Handedness Questionnaire) [Oldfield, 1971], (3) report no adverse health conditions, physical incapacities or neurological disorders, (4) report no use of medications that influenced central nervous system function, (5) have a corrected visual acuity of 20/20 and no color blindness, (6) successfully perform a 'mock MRI' session to test for body size compatibility with an MRI machine and to screen for claustrophobia, and (7) sign an informed assent approved by the University of Illinois at Urbana-Champaign. A legal guardian also provided written informed consent in accordance with the Institutional Review Board of the University of Illinois at Urbana-Champaign. The subjects were compensated for participation.

Aerobic Fitness Assessment

The aerobic fitness level of each child was determined by measuring maximal oxygen consumption ( $\mathrm{VO}_{2}$ max.) using a computerized indirect calorimetry system (ParvoMedics True Max 
2400) during a modified Balke protocol [American College of Sports Medicine, 2006]. Specifically, the participants ran on a motor-driven treadmill at a constant speed with increases in grade increments of $2.5 \%$ every 2 min until volitional exhaustion. Averages for oxygen uptake $\left(\mathrm{VO}_{2}\right)$ and respiratory exchange ratio (the ratio between carbon dioxide and oxygen percentage) were assessed every $30 \mathrm{~s}$. In addition, the heart rate was measured throughout the fitness test [using a Polar heart rate monitor (Polar WearLink ${ }^{\circledR}+31$, Polar Electro, Finland)], and ratings of perceived exertion were assessed every 2 min using the children's OMNI scale [Utter et al., 2002].

$\mathrm{VO}_{2}$ max. was defined when oxygen consumption remained at a steady state despite an increase in workload. The relative peak oxygen consumption was based upon maximal effort as evidenced by (1) a peak heart rate $>185$ beats per minute [American College of Sports Medicine, 2006] accompanied by a heart rate plateau (i.e. an increase in work rate with no concomitant increase in heart rate) [Freedson and Goodman, 1993], (2) respiratory exchange ratio $>1.0$ [Bar-Or, 1983], and/or (3) ratings on the children's OMNI scale of perceived exertion $>8$ [Utter et al., 2002]. The relative peak oxygen consumption was expressed in milliliters/kilogram/minute.

Fitness group assignments (i.e. higher-fit and lower-fit) were based on whether a child's $\mathrm{VO}_{2}$ max. value fell above the 70th percentile or below the 30th percentile according to normative data provided by Shvartz and Reibold [1990]. Children who did not qualify as higher-fit or lower-fit were excluded from participation.

\section{Sample}

Fifty-nine subjects were initially eligible for the present study (after exclusions due to Kaufman Brief Intelligence Test scores, $\mathrm{ADHD}$, pubertal timing, $\mathrm{VO}_{2}$ max. criteria, etc.). Additional subjects were excluded due to poor scan quality because of excessive motion $(n=3)$ and basal ganglia volume outliers $(n=1)$.

Analyses were conducted on a total of 55 subjects, including 25 higher-fit children ( 14 boys, 11 girls) with an average age of 10.0 years ( $\mathrm{SD}=0.6$; range $9-10$ ) and 30 lower-fit children (11 boys, 19 girls) with an average age of 10.0 years $(\mathrm{SD}=0.6$; range $9-10)$. No statistically reliable differences in age, gender, socioeconomic status or Kaufman Brief Intelligence Test scores existed between the fitness groups. Table 1 provides a list of demographic and fitness information for the final sample.

\section{MR Imaging Protocol and Image Processing}

For all participants, high-resolution $(1.3 \mathrm{~mm} \times 1.3 \mathrm{~mm} \times 1.3$ $\mathrm{mm}) \mathrm{T}_{1}$-weighted structural brain images were acquired using a 3D MPRAGE (magnetization prepared rapid gradient echo imaging) protocol with 144 contiguous axial slices, collected in ascending fashion parallel to the anterior and posterior commissures (echo time $=3.87 \mathrm{~ms}$, repetition time $=1,800 \mathrm{~ms}$, field of view $=256 \mathrm{~mm}$, acquisition matrix $192 \mathrm{~mm} \times 192 \mathrm{~mm}$, slice thickness $=1.3 \mathrm{~mm}$ and flip angle $=8^{\circ}$ ). All images were collected on a 3 T head-only Siemens Allegra MRI scanner.

Segmentation and volumetric analysis of the left and right dorsal striatum (i.e. caudate nucleus and putamen), ventral striatum (i.e. nucleus accumbens) and globus pallidus were performed using a semiautomated, model-based subcortical tool (FMRIB's Integrated Registration and Segmentation Tool) in FMRIB's Software Library version 4.1.4 [Patenaude, 2007; Patenaude et al., 2007a; Patenaude et al., 2007b]. To begin, a 2-stage affine registra-
Table 1. Participant mean demographic and fitness data by aerobic fitness group

\begin{tabular}{lcc}
\hline Variable & Lower-fit & Higher-fit \\
\hline Participants & $30(11$ male $)$ & $25(14$ male $)$ \\
Age, years & $10.0(0.6)$ & $10.0(0.6)$ \\
VO $_{2}$ max., ml/kg/min & $36.5(3.9)^{*}$ & $52.5(4.8)^{*}$ \\
K-BIT composite score (IQ) & $114.6(14.9)$ & $114.4(7.6)$ \\
K-BIT crystallized score & & \\
$\quad$ (vocabulary) & $110.8(11.7)$ & $109.4(7.5)$ \\
K-BIT fluid score (matrices) & $115.4(17.6)$ & $116.5(9.2)$ \\
SES (median) & $2.8(0.6)$ & $2.6(0.6)$ \\
ADHD & $5.9(3.8)$ & $7.1(4.1)$
\end{tabular}

Figures in parentheses represent SD. K-BIT $=$ Kaufman Brief Intelligence Test [Kaufman and Kaufman, 1990]; SES = socioeconomic status. SES was determined by the creation of a trichotomous index based on 3 variables: child participation in a free or reduced-price lunch program at school, the highest level of education obtained by the child's mother and father, and the number of parents who worked full-time [Birnbaum et al., 2002]. ADHD: scores on the ADHD Rating Scale V [DuPaul et al., 1998].

${ }^{*} \mathrm{p}<0.001$ : significantly different.

tion to a standard space template (MNI space) with $1 \mathrm{~mm}$ resolution using 12 degrees of freedom and a subcortical mask to exclude voxels outside the subcortical regions was performed on each subject's MPRAGE. Next, the caudate nucleus, putamen, nucleus accumbens and globus pallidus were segmented with 30, 40, 50 and 40 modes of variation for each structure, respectively. Please refer to Erickson et al. [in press] and Patenaude et al. [2007a, b] for a description of the FIRST methodology. Previous studies have reported high test-retest reliability of this segmentation algorithm [Erickson et al., in press].

Segmentations were visually checked for errors, and no errors were noted. Finally, boundary correction was run, a process which classifies boundary voxels as belonging to the structure (or not) based on a statistical probability ( $\mathrm{z}$-score $>3.00$; $\mathrm{p}<0.001)$. The volume of each participant's caudate nucleus, putamen, nucleus accumbens and globus pallidus was measured in cubic millimeters, and these values were used in all subsequent analyses. See figure 1 for a sample FIRST segmentation of the basal ganglia.

\section{Flanker Task}

The flanker task is a selective attention paradigm, often employed to examine interference control, one aspect of executive control [Eriksen and Eriksen, 1974; Kramer et al., 1994]. The eventrelated task required individuals to respond as quickly as possible to the direction of a central arrow in an array of arrows presented on an MRI back-projection. A congruent trial consisted of $>>>>>$ and $<<<<<$ arrow displays in which the target arrow was flanked by arrows of the same direction. An incongruent trial consisted of $>><>$ and $<<><<$ displays in which the target arrow was flanked by the opposing arrow response. Trials in which the middle arrow pointed to the right (e.g. $>>>>>,<<><<$ ) required a right 


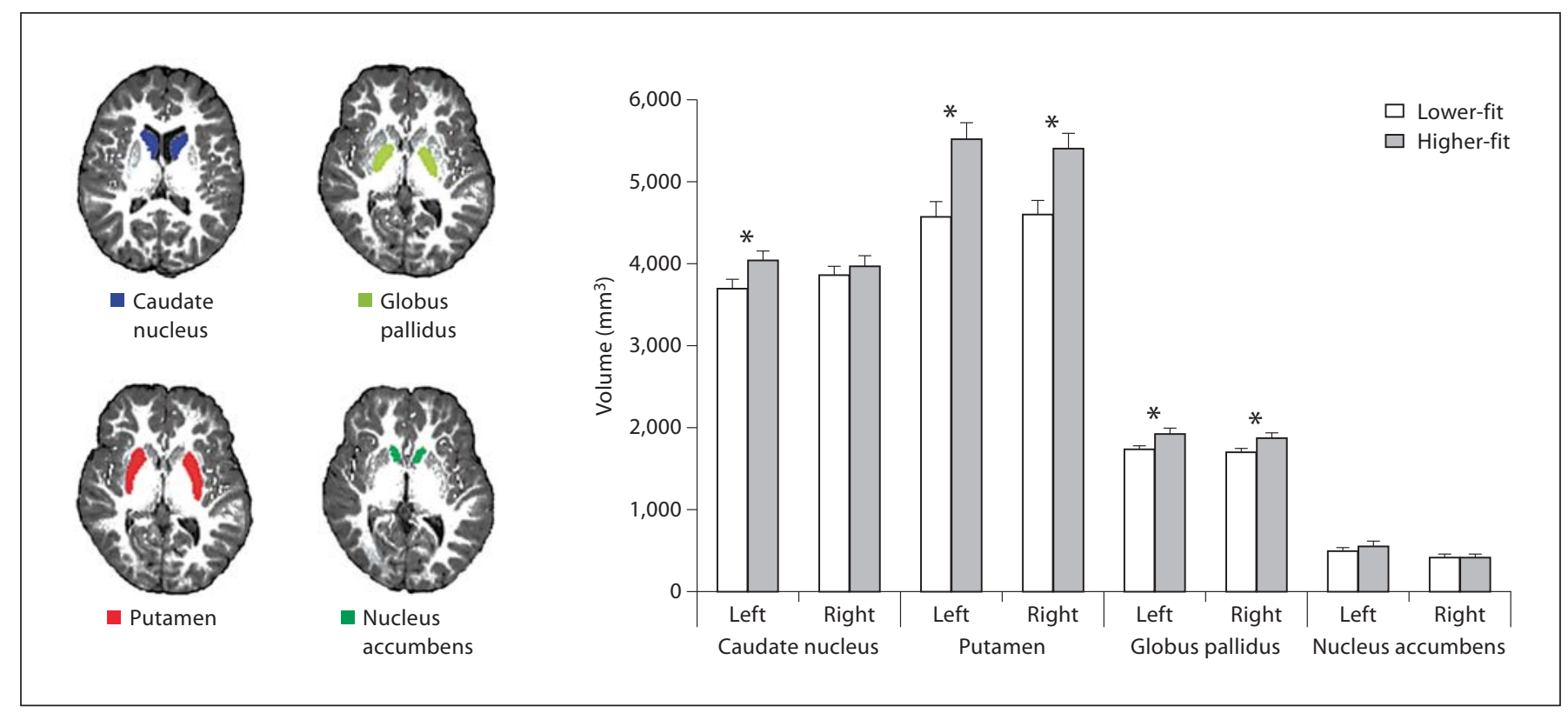

Fig. 1. FIRST segmentations of the bilateral caudate nucleus (blue), putamen (red), globus pallidus (yellow) and nucleus accumbens (green) on a structural brain reconstruction as well as basal ganglia volumes (adjusted by total intracranial volume) as a function of aerobic fitness group (error bars represent standard error). ${ }^{*} \mathrm{p}<0.05$.

index finger button press (via an MRI-compatible response box), while trials in which the middle arrow pointed to the left (e.g. $<<<<,>><>>$ ) required a left index finger button press.

During the task, 20 trials of each of the 4 possible arrow presentations $(>>)>>,<<<<<,<<><<,>><>>)$ ) were shown in a random order. Each array of arrows was presented for $1,500 \mathrm{~ms}$, and each stimulus array was separated by a fixation cross (+) presented for 1,500 ms. Forty additional fixation crosses that jittered between 1,500 and 6,000 ms were also randomly presented after the constant 1,500-ms fixation cross throughout the task. The jitter prevented participants from expecting a specific frequency of responding. White arrows and white fixation crosses were presented on a black background. The participant was engaged in the task for about $6 \mathrm{~min}$, in addition to a 1-min block of 20 practice trials ( 5 of each arrow arrays, presented randomly). Stimulus presentation, timing and task performance measures were controlled by E-Prime software.

\section{Results}

\section{Participant Demographics}

Demographic and fitness data are provided in table 1. None of the demographic variables (i.e. age, IQ, socioeconomic status, ADHD) differed between higher-fit and lower-fit groups. Higher-fit children had higher $\mathrm{VO}_{2}$ max. scores than lower-fit participants as revealed by an independent $t$ test $[\mathrm{t}(53)=13.69, \mathrm{p}<0.001]$.

\section{Aerobic Fitness and Flanker Performance}

Table 2 provides means (SD) for reaction time (RT) and response accuracy for congruent and incongruent conditions of the flanker task for higher-fit and lower-fit groups.

To investigate the amount of behavioral interference engendered by incongruent flanking items, a percent interference score was computed for each participant as the percent increase in RT to incongruent stimuli, over and above the average RT to congruent stimuli [i.e. ([(incongruent - congruent)/congruent] $\times$ 100)] [Colcombe et al., 2004]. This measure was derived to reflect interference unbiased by differences in base RT. Only correct responses were included in the outcome measure.

The results of an independent $t$ test revealed that higher-fit children $(\mathrm{M}=5.17 \%$; $\mathrm{SD}=7.44 \%)$ showed less percent interference compared to lower-fit children $(\mathrm{M}=$ $10.86 \% ; \mathrm{SD}=11.58 \%)[\mathrm{t}(53)=2.20, \mathrm{p}=0.032]$ (see table 2 ). This suggests that higher-fit children (5\% interference) are more efficient at managing conflicting cues compared to lower-fit preadolescents (11\% interference). There were no significant fitness-based differences in flanker accuracy (all $\mathrm{p}>0.15$ ) (although an examination of the means indicated that higher-fit children showed a trend for superior accuracy for congruent and incongruent trials). 
Table 2. Task performance by aerobic fitness group for congruent and incongruent conditions of the flanker task

\begin{tabular}{lcc}
\hline Measure & Lower-fit & Higher-fit \\
\hline Mean congruent RT, ms & $742.9(97.1)$ & $746.7(64.0)$ \\
Mean incongruent RT, ms & $821.4(122.9)$ & $786.1(97.0)$ \\
Congruent response accuracy, \% & $88.3(17.8)$ & $93.6(7.7)$ \\
Incongruent response accuracy, \% & $85.6(15.7)$ & $90.7(15.2)$ \\
Percent interference RT, \% & $10.9(11.6)^{*}$ & $5.2(7.4)^{*}$ \\
\hline
\end{tabular}

Figures in parentheses represent SD: ${ }^{*} \mathrm{p}<0.05$ : significantly different.

\section{Aerobic Fitness and Basal Ganglia Volumes}

A multivariate analysis of variance indicated a significant effect of aerobic fitness group on basal ganglia volume $[\mathrm{F}(8,46)=2.89, \mathrm{p}=0.01]$. This effect was significant with and without total intracranial volume (the sum of total gray matter, white matter and cerebrospinal fluid) as a covariate. To decompose the effects of the omnibus analysis, univariate ANCOVAs were conducted to compare basal ganglia volumes as a function of aerobic fitness group, with total intracranial volume (cubic millimeters) as a covariate to control for variation in head size. The results of these ANCOVAs are reported below, and table 3 and figure 1 provide mean basal ganglia volumes as a function of aerobic fitness group. Identical ANCOVA results were found when total gray matter volume was used as a covariate, when both total intracranial volume and total gray matter volume were inserted as covariates, and without covariates. Higher-fit and lower-fit children did not show differences in total gray matter volume, total white matter volume, total cerebrospinal fluid or total intracranial volume (all $\mathrm{t}>0.07, \mathrm{p}>0.46$ ). In addition, there were no significant effects of gender on striatum volumes after total intracranial volume was controlled (all $\mathrm{F}<0.7$, $\mathrm{p}>0.4$ ).

Caudate Nucleus. Higher-fit children showed larger left caudate nucleus volumes compared to lower-fit children $[F(1,52)=4.24, p=0.04]$. No fitness-based differences in volume were found for the right caudate nucleus $[\mathrm{F}(1,52)=0.58, \mathrm{p}=0.45]$.

Putamen. Higher-fit children showed larger left putamen volumes $[\mathrm{F}(1,52)=13.80, \mathrm{p}<0.0001]$ and larger right putamen volumes $[\mathrm{F}(1,52)=11.40, \mathrm{p}=0.001]$ compared to lower-fit children.

Globus Pallidus. Higher-fit children showed larger left globus pallidus volumes $[\mathrm{F}(1,52)=8.43, \mathrm{p}=0.005]$ and
Table 3. Participant unadjusted mean basal ganglia volumes (square millimeters) by aerobic fitness group

\begin{tabular}{lll}
\hline Variable & Lower-fit & Higher-fit \\
\hline Left caudate nucleus* & $3,692.15(722.13)$ & $4,061.92(464.82)$ \\
Right caudate nucleus & $3,836.29(716.60)$ & $4,017.73(568.31)$ \\
Left putamen* & $4,570.68(1,065.20)$ & $5,554.15(775.64)$ \\
Right putamen* & $4,588.01(1,046.08)$ & $5,456.07(734.18)$ \\
Left globus pallidus* & $1,720.01(303.33)$ & $1,947.80(243.23)$ \\
Right globus pallidus* & $1,695.66(283.44)$ & $1,898.53(229.29)$ \\
Left nucleus accumbens & $486.87(248.94)$ & $566.59(219.42)$ \\
Right nucleus accumbens & $402.29(192.07)$ & $419.24(200.19)$ \\
\hline
\end{tabular}

Figures in parentheses represent SD. ${ }^{*} \mathrm{p}<0.05$ : significantly different.

larger right globus pallidus volumes $[\mathrm{F}(1,52)=7.61, \mathrm{p}=$ 0.008] compared to lower-fit children.

Nucleus Accumbens. There were no fitness differences in left $[\mathrm{F}(1,52)=1.20, \mathrm{p}=0.28]$ or right $[\mathrm{F}(1,52)=0.03$, $\mathrm{p}=0.85]$ nucleus accumbens volumes.

\section{Basal Ganglia Volume and Flanker Performance}

Caudate Nucleus. There were no significant Spearman correlations between left or right caudate nucleus volumes and flanker performance (i.e. accuracy or response times) (all $\mathrm{r}<0.200, \mathrm{p}>0.100)$.

Putamen. Left putamen volume was negatively correlated with flanker percent interference $(r=-0.333, p=$ 0.01 ). The correlation between right putamen volume and percent interference was marginally significant $(\mathrm{r}=$ $-0.247, \mathrm{p}=0.06$ ). Right putamen volume was also positively correlated with accuracy during incongruent flanker task trials $(\mathrm{r}=0.266, \mathrm{p}=0.05)$.

Globus Pallidus. Left $(\mathrm{r}=-0.261, \mathrm{p}=0.05)$ and right $(\mathrm{r}=-0.350, \mathrm{p}=0.009)$ globus pallidus volumes were negatively correlated with flanker percent interference.

Nucleus Accumbens. No significant correlations between nucleus accumbens volume and flanker task performance were found (all $r<0.210$, $\mathrm{p}>0.100$ ).

\section{Discussion}

The results revealed an association between aerobic fitness, the volume of the dorsal striatum and flanker task performance. Specifically, children with higher aerobic fitness levels showed less behavioral interference to mis- 
leading and irrelevant flanking cues, coupled with a larger dorsal striatum (i.e. left caudate nucleus and bilateral putamen). By the same accord, putamen volumes of the dorsal striatum were negatively correlated with flanker percent interference scores. The results support the claim that the dorsal striatum is involved in cognitive control, motor integration and response resolution [Aron et al., 2009], processes associated with the performance of the flanker task. That is, during the stimulus-response paradigm, subjects must successfully prepare and initiate motor responses, flexibly switch between congruent and incongruent trials, and inhibit/filter incongruent and irrelevant information (provided by incongruent flanking cues). Furthermore, the results support studies which suggest that these cognitive processes are amenable to aerobic fitness across the lifespan [Hillman et al., 2009; Kramer et al., 1999].

No association between aerobic fitness, task performance and ventral striatum volume was observed. The nucleus accumbens is said to involve low-level limbic and reward processes, functions less involved during the selective attention and interference control paradigm. That is, subjects were not provided feedback during the task and thus were unable to adjust response selection based on reinforcement.

In addition, the results reveal a link between childhood aerobic fitness, globus pallidus volume and flanker task performance. After cortical and dopaminergic inputs have been integrated in the striatum, basal ganglia output converges in the globus pallidus [Aron et al., 2009; Di Martino et al., 2008; Draganski et al., 2008]. The present results raise the possibility that aerobic fitness interacts with both input and output basal ganglia regions, resulting in a direct effect on behavior.

Human studies across the lifespan have predominantly focused on the positive relation of aerobic fitness to executive control processes and prefrontal neural networks [Colcombe and Kramer, 2003; Hillman et al., 2008, but see Erickson et al., 2009]. The presence of cortex-striatal loops emphasizes the tight functional and anatomical connections between the basal ganglia and frontal cortical systems involved in the cognitive control of attention, response inhibition, working memory and executive function [Aron et al., 2009; Casey et al., 1997; Liston et al., 2006]. Given the well-established effect of aerobic fitness on prefrontal cortex structure and function, it is plausible that aerobic fitness also impacts subcortical regions connected to the frontal cortex. While the current study is limited to conclusions about subcortical structures given the chosen brain segmentation tech- nique, future investigations should examine the role of visual, parietal and frontal cortical areas as well as cortical-striatal connectivity in the association between childhood fitness and flanker task performance. A study of the duration of fitness effects on childhood neurocognition as well as the effects of a physical activity intervention on basal ganglia structure and function are also important avenues for future research.

Together, the behavioral and structural imaging results suggest that higher-fit children exhibit larger volumes in specific subregions of the basal ganglia, which may impact flanker task performance. The results are important because they provide additional support suggesting that cognitive enhancement through increased fitness is directly related to differential volumes of brain regions involved in cognitive function [Hillman et al., 2008; Chaddock et al., 2010]. In addition, it seems that childhood aerobic fitness not only impacts the hippocampus; it also affects the structure and function of the basal ganglia. Nevertheless, the results suggest that aerobic fitness does not have a general impact on the volume of all structures in the brain, but rather that there is some specificity, given that dorsal but not ventral striatal structures were associated with aerobic fitness.

The results have important public health and educational implications, given the rise of childhood sedentary behaviors and obesity rates as well as the reduction and elimination of physical activity opportunities in schools [Baker et al., 2007; Hillman et al., 2008; Ludwig, 2007; Olshansky et al., 2005]. The present findings suggest that high levels of aerobic fitness in children can positively impact structural volumes of the basal ganglia involved in learning and cognitive control, two essential functions involved in academic success. Hopefully, the present findings will encourage modifications of educational and health care policies which emphasize the importance of physical activity on physical and cognitive health.

\section{Acknowledgements}

We would like to thank Nancy Dodge and Holly Tracy for their help with data collection. 


\section{References}

- Aguiar AS, Speck AE, Prediger RD, Kapczinski F, Pinho RA (2008): Downhill training upregulates mice hippocampal and striatal brain-derived neurotrophic factor levels. J Neural Transm 115:1251-1255.

American College of Sports Medicine (2006): ACSM's Guidelines for Exercise Testing and Prescription, ed 7. New York, Lippincott Williams \& Wilkins, p 366.

Aron AR, Poldrack RA, Wise SP (2009): Cognition: basal ganglia role; in Squire LR (ed.): Encyclopedia of Neuroscience, vol 2, pp 1069-1077.

Baker JL, Olsen LW, Sorensen TIA (2007): Childhood body-mass index and risk of coronary heart disease in adulthood. N Engl J Med 357:2329-2337.

Bar-Or O (1983): Pediatric sports medicine for the practitioner: From physiologic principles to clinical applications. New York, Springer, p 376 .

-Birnbaum AS, Lytle LA, Murray DM, Story M, Perry CL, Boutelle KN (2002): Survey development for assessing correlates of young adolescents' eating. Am J Health Behav 26:284295.

Buck SM, Hillman CH, Castelli DM (2008): The relation of aerobic fitness to Stroop task performance in preadolescent children. Med Sci Sports Exerc 40:166-172.

Casey BJ, Getz S, Galvan A (2008): The adolescent brain. Dev Rev 28:62-77.

-Casey BJ, Thomas KM, Welsh TF, Badgaiyan $\mathrm{RD}$, Eccard $\mathrm{CH}$, Jennings JR, Crone EA (2000): Dissociation of response conflict, attentional selection, and expectancy with functional magnetic resonance imaging. Proc Natl Acad Sci 97:8728-8733.

-Casey BJ, Trainor RJ, Orendi JL, Schubert AB, Nystrom LE, Giedd JN, Castellanos FX, Haxby JV, Noll DC, Cohen JD, Forman SD, Dahl RE, Rapoport JL (1997): A developmental functional MRI study of prefrontal activation during performance of a go-no-go task. J Cog Neurosci 9:835-847.

-Castelli DM, Hillman CH, Buck SM, Erwin HE (2007): Physical fitness and academic achievement in third- and fifth-grade students. J Sport Exerc Psychol 29:239-252.

Chaddock L, Erickson KI, Prakash RS, Kim JS, Voss MW, VanPatter M, Pontifex MB, Raine $\mathrm{LB}$, Konkel A, Hillman $\mathrm{CH}$, Cohen NJ, Kramer AF (2010): A neuroimaging investigation of the association between aerobic fitness, hippocampal volume and memory performance in preadolescent children. Development \& Aging. Abstr Cogn Neurosci Soc B82-76.

Chaddock L, Hillman CH, Buck SM, Cohen NJ (in press): Aerobic fitness and executive control of relational memory in preadolescent children: MSSE.
-Chomitz VR, Slining MM, McGowan RJ, Mitchell SE, Dawson GF, Hacker KA (2009): Is there a relationship between physical fitness and academic achievement? Positive results from public school children in the northeastern United States. J Sch Health 79: 30-37.

Colcombe S, Kramer AF (2003): Fitness effects on the cognitive function of older adults: A meta-analytic study. Psychol Sci 14:125-130.

Colcombe SJ, Kramer AF, Erickson KI, Scalf P, McAuley E, Cohen NJ, Webb A, Jerome GJ, Marquez DX, Elavsky S (2004): Cardiovascular fitness, cortical plasticity, and aging. PNAS 101:3316-3321.

-Cotman CW, Berchtold NC (2002): Exercise: a behavioral intervention to enhance brain health and plasticity. Trends Neurosci 25 : 295-301.

-Di Martino A, Scheres A, Marguiles DS, Kelly AM, Uddin LQ, Shehzad Z, Biswal B, Walters JR, Castellanos FX, Milham MP (2008): Functional connectivity of human striatum: a resting state fMRI study. Cereb Cortex 18 2735-2747.

Ding YH, Luan XD, Li J, Rafols JA, Guthinkonda M, Diaz FG, Ding Y (2004): Exercise-induced overexpression of angiogenic factors and reduction of ischemia/reperfusion injury in stroke. Curr Neurovasc Res 1:411-420.

Draganski B, Kherif F, Kloppel S, Cook PA, Alexander DC, Parker GJ, Deichmann R, Ashburner J, Frackowiak RS (2008): Evidence for segregated and integrative connectivity patterns in the human basal ganglia. J Neurosci 28:7143-7152.

DuPaul GJ, Power TJ, Anastopoulos A, Reid R (1998): ADHD Rating Scale - IV: Checklists, Norms, and Clinical Interpretation. New York, Guilford Press.

Erickson KI, Boot WR, Basak C, Neider MR, Prakash RS, Voss MW, Graybiel AM, Simons DJ, Fabiani M, Gratton G, Kramer AF (in press): Striatal volume predicts level of video game skill acquisition.

Erickson KI, Prakash RS, Voss MW, Chaddock L, Hu L, Morris KS, White SM, Wojcicki TR, McAuley E, Kramer AF (2009): Aerobic fitness is associated with hippocampal volume in elderly humans. Hippocampus 19:10301039 .

Eriksen BA, Eriksen CW (1974): Effects of noise letters on the identification of a target letter in a nonsearch task. Percept Psychophys 16: $143-149$

Freedson PS, Goodman TL (1993): Measurement of oxygen consumption; in Rowland TW (ed): Pediatric Laboratory Exercise Testing: Clinical Guidelines. Human Kinetics, Champaign, pp 91-113.

Graybiel AM (2005): The basal ganglia: learning new tricks and loving it. Curr Opin Neurobiol 15:638-644.

Graybiel AM (2008): Habits, rituals and the evaluative brain. Annu Rev Neurosci 31:359-387.
Hillman CH, Buck SM, Themanson JR, Pontifex MB, Castelli DM (2009): Aerobic fitness and cognitive development: event-related brain potential and task performance of executive control in preadolescent children. Dev Psychol 45:114-129.

-Hillman CH, Castelli DM, Buck SM (2005): Aerobic fitness and neurocognitive function in healthy preadolescent children. Med Sci Sports Exerc 37:1967-1974.

Hillman CH, Erickson KI, Kramer AF (2008): Be smart, exercise your heart: exercise effects on brain and cognition. Nature Rev Neurosci 9: 58-65.

Kaufman AS, Kaufman NL (1990): Kaufman Brief Intelligence Test. Circle Pines, AGS.

Kramer AF, Hahn S, Cohen N, Banich M, McAuley E, Harrison C, Chason J, Vakil E, Bardell L, Boileau RA, Colcombe A (1999): Aging, fitness, and neurocognitive function. Nature 400:418-419.

- Kramer A, Humphrey D, Larish J, Logan G, Strayer D (1994): Aging and inhibition: beyond a unitary view of inhibitory processing in attention. Psychol Aging 9:491-512.

- Li J, Ding YH, Rafols JA, Lai Q, McAllister JP, Ding Y (2005): Increased astrocyte proliferation in rats after running exercise. Neurosci Lett 386:160-164.

- Liston C, Watts R, Tottenham N, Davidson MC, Niogi S, Ulug AM, Casey BJ (2006): Frontostriatal microstructure modulates efficient recruitment of cognitive control. Cereb Cortex 16:553-560.

-Lopez-Lopez C, LeRoith D, Torres-Aleman I (2004): Insulin-like growth factor I is required for vessel remodeling in the adult brain. Proc Natl Acad Sci USA 101:98339838.

Ludwig DS (2007): Childhood obesity: the shape of things to come. N Engl J Med 357:23252327.

Marais L, Stein DJ, Daniels WM (2009): Exercise increases BDNF levels in the striatum and decreases depressive-like behavior in chronically stressed rats. Metab Brain Dis 24:587597.

- Marques E, Vasconcelos F, Rolo MR, Pereira FC, Silva AP, Macedo TR, Ribeiro CF (2008): Influence of chronic exercise on the amphetamine-induced dopamine release and neurodegeneration in the striatum of the rat. Ann NY Acad Sci 1139:222-231.

- Neeper S, Gomez-Pinilla F, Choi J, Cotman CW (1995): Exercise and brain neurotrophins. Nature 373:109.

Oldfield RC (1971): The assessment and analysis of handedness: the Edinburgh inventory. Neuropsychologia 9:97-113.

-Olshansky SJ, Passaro DJ, Hershow RC, Layden J, Carnes BA, Brody J, Hayflick L, Butler RN, Allison DB, Ludwig DS (2005): A potential decline in life expectancy in the United States in the 21st century. N Engl J Med 352: $1138-1143$ 
Patenaude B (2007): Bayesian statistical models of shape and appearance for subcortical brain segmentation (D. Phil. thesis). Oxford, University of Oxford.

Patenaude B, Smith SM, Kennedy D, Jenkinson M (2007a): FIRST-FMRIB's integrated registration and segmentation tool. Chicago, Human Brain Mapping Conference.

Patenaude B, Smith SM, Kennedy D, Jenkinson M (2007b): Bayesian shape and appearance models. Technical report TR07BP1. Oxford, FMRIB Center, University of Oxford.

Ragozzino ME, Jih J, Tzavos A (2002): Involvement of the dorsomedial striatum in behavioral flexibility: role of muscarinic cholinergic receptors. Brain Res 953:205-214.

- Shi LH, Luo F, Woodward DJ, Chang JY (2004): Neural responses in multiple basal ganglia regions during spontaneous and treadmill locomotion tasks in rats. Exp Brain Res 157: 303-314.
Shvartz E, Reibold RC (1990): Aerobic fitness norms for males and females aged 6 to 75 years: a review. Aviat Space Environ Med 61: 3-11.

Sibley BA, Etnier JL (2003): The relationship between physical activity and cognition in children: a meta-analysis. Pediatr Exerc Sci 15: 243-256.

Tanner JM (1962): Growth at Adolescence. Oxford, Blackwell Scientific Publications, p 340.

Taylor SJC, Whincup PH, Hindmarsh PC, Lampe F, Odoki K, Cook DG (2001): Performance of a new pubertal self-assessment questionnaire: a preliminary study. Paediatr Perinat Epidemiol 15:88-94.

Tillerson JL, Cohen AD, Philhower J, Miller GW, Zigmond MJ, Schallert T (2001): Forced limb-use effects on the behavioral and neurochemical effects of 6-hydroxydopamine. J Neurosci 21:4427-4435.
Utter AC, Roberson RJ, Nieman DC, Kang J (2002): Children's OMNI scale of perceived exertion: walking/running evaluation. Med Sci Sports Exerc 34:139-144.

Van Praag H, Christie BR, Sejnowski TJ, Gage FH (1999): Running enhances neurogenesis, learning, and long-term potentiation in mice. Neurobiology 96:13427-13431.

-Van Praag H, Shubert T, Zhao C, Gage FH (2005): Exercise enhances learning and hippocampal neurogenesis in aged mice. J Neurosci 25:8680-8685.

Vaynman S, Ying Z, Gomez-Pinilla F (2004): Hippocampal BDNF mediates the efficacy of exercise on synaptic plasticity and cognition. Eur J Neurosci 20:2580-2590.

Wylie SA, van den Wildenberg WP, Ridderinkhof KR, Bashore TR, Powell VD, Manning CA, Wooten GF (2009): The effect of Parkinson's disease on interference control during action selection. Neuropsychologia 47:145157. 